\title{
Causas de aborto bovino diagnosticadas no Setor de Patologia Veterinária da UFRGS de 2003 a $2011^{1}$
}

\author{
Nadia A.B. Antoniassi², Gregory D. Juffo², Adriana S. Santos ${ }^{3}$, Caroline A. Pescador ${ }^{4}$, \\ Luis G. Corbellini ${ }^{5}$ e David Driemeier ${ }^{2 *}$
}

\begin{abstract}
Antoniassi N.A.B., Juffo G.D., Santos A.S., Pescador C.A., Corbellini L.G. \& Driemeier D. 2013. [Causes of bovine abortion diagnosed by the Sector of Veterinary Pathology of the Federal University of Rio Grande do Sul in the years 2003-2011.] Causas de aborto bovino diagnosticadas no Setor de Patologia Veterinária da UFRGS de 2003 a 2011. Pesquisa Veterinária Brasileira 33(2):155-160. Setor de Patologia Veterinária, Faculdade de Veterinária, Universidade Federal do Rio Grande do Sul, Av. Bento Gonçalves 9090, Porto Alegre, RS 91540-000, Brazil. E-mail: davetpat@ufrgs.br

The main causes of abortion in cattle diagnosed from January 2003 to December 2011 are described. A total of 490 fetuses from several Brazilian states were evaluated. Specific causes of abortion were found in $46.7 \%$ of the cases, and protozoan abortions, especially by Neospora caninum, were detected in 33\% (162/490). Bacterial abortions corresponded to $6.3 \%(31 / 490)$, followed by fungal ones to $0.8 \%$ (4/490). In two aborted fetuses $(0.4 \%)$, a co-infection with two agents could be identified. Non-infectious diseases could be associated with $3 \%$ of the abortions and congenital malformations with $2.6 \%$.
\end{abstract}

INDEX TERMS: Fetuses, causes of bovine abortion, Neospora caninum.

RESUMO.- Descrevem-se as causas de aborto bovino diagnosticadas no Setor de Patologia Veterinária da Universidade Federal do Rio Grande do Sul no período de janeiro de 2003 a dezembro de 2011. Um total de 490 fetos bovinos foi analisado neste período. Causas específicas de aborto foram encontradas em 46,7\% dos casos. Infecções por protozoários, em especial Neospora caninum acometeram 33\% dos casos (162/490). Bactérias com 6,3\% (31/490), seguidas por fungos com $0,8 \%$ (4/490) dos casos, foram causas

${ }^{1}$ Recebido em 20 de junho de 2012.

Aceito para publicação em 12 de julho de 2012.

Parte da tese de doutorado do primeiro autor pelo Curso de Pós-Graduação em Ciências Veterinárias, área de concentração em Cirurgia, Morfologia e Patologia Animal, Universidade Federal do Rio Grande do Sul (UFRGS).

${ }^{2}$ Laboratório de Patologia Veterinária, Departamento de Patologia Clínica Veterinária, Faculdade de Medicina Veterinária (Favet), Universidade Federal do Rio Grande do Sul (UFRGS), Av. Bento Gonçalves 9090, Porto Alegre, RS 91540-000, Brasil.*Autor para correspondência: davetpat@ufrgs.br

${ }^{3}$ Doutoranda Setor de Patologia Veterinária, Escola de Veterinária e Zootecnia, Universidade Federal de Goiás (UFG), Campus Samambaia, Rodov. GO 462 Goiânia-Nova Veneza Km 0, Goiânia, GO 74001-970, Brasil.

${ }^{4}$ Laboratório de Patologia Veterinária, Departamento de Clínica Médica Veterinária, Universidade Federal de Mato Grosso (UFMT). Av. Fernando Correa da Costa 2367, Boa Esperança, Cuiabá, MT 78060-900, Brasil.

${ }^{5}$ Laboratório de Epidemiologia (Epilab), Favet-UFRGS, Porto Alegre, RS. adicionais de abortos. Em dois fetos $(0,4 \%)$, coinfecções por dois agentes foram identificadas. Causas não-infecciosas foram observadas em 3\% dos abortos e Malformações congênitas em 2,6\%.

TERMOS DE INDEXAÇAO: Feto, causas de aborto bovino, Neospora caninum.

\section{INTRODUÇÃO}

A mortalidade fetal é causa importante de perdas reprodutivas em animais domésticos e tem impacto significativo na rentabilidade de sistemas de produção animal. No Rio Grande do Sul, relatos de abortos em bovinos são frequentes e contribuem para os baixos índices de prenhez e nascimentos verificados na região (Fernandes 1998). A determinação das causas do aborto é fundamental no controle sanitário dos rebanhos; entretanto, a tarefa é difícil e somente em $30 \%$ dos fetos bovinos abortados analisados, obtém-se diagnóstico etiológico definitivo, em virtude das múltiplas causas envolvidas, já que muitos agentes, infecciosos ou não, podem estar envolvidos (Miller 1987, Kirkbride 1990, Kirkbride 1991, Jamaluddin et al. 1996).

No Brasil, poucas informações são disponíveis sobre causas de aborto em bovinos. Em estudo realizado por Corbellini et al. (2006a) em fetos bovinos abortados no sul do Brasil, o diagnóstico etiológico foi obtido em 51,5 \% dos 
161 fetos analisados, dos quais, $88 \%$ foram associados a agentes infecciosos, com destaque para Neospora caninum. Esse trabalho descreve as principais causas de aborto bovino diagnosticadas no Setor de Patologia Veterinária da Universidade Federal do Rio Grande do Sul no período de 2003 à 2011.

\section{MATERIAL E MÉTODOS}

\section{Aspectos gerais}

Um estudo retrospectivo foi realizado nos arquivos de laudos de fetos bovinos examinados, desde janeiro de 2003 até dezembro de 2011. Os dados obtidos nesses laudos foram computados e analisados. Aborto bovino foi definido como a expulsão do feto vivo ou morto do útero, a partir de 42 dias até, aproximadamente, 260 dias de gestação, quando esse é incapaz de exercer uma vida independente, em um ambiente extra-uterino (Hubbert et al. 1972). Cada aborto, mesmo quando múltiplo, foi considerado um caso.

Os fetos foram, geralmente, encaminhados inteiros, refrigerados, ou congelados e, por vezes, acompanhados de placenta e de uma ficha com dados da propriedade e do animal abortado. Em determinados casos, os fetos foram necropsiados pelo veterinário, a campo e somente fragmentos teciduais foram encaminhados para análise, tanto congelados como refrigerados.

\section{Necropsia e colheita de material}

A necropsia fetal incluiu exame externo e a estimativa da idade fetal conforme medida do comprimento da nuca até a inserção da cauda (Barr et al. 1990), ou, quando disponível, através dos registros de cobertura. Fragmentos de encéfalo, pulmão, coração, fígado, rim, músculo esquelético, timo, baço, abomaso, pálpebra e placenta (ocasionalmente presente), foram coletados, fixados em formalina tamponada $10 \%$, processadas rotineiramente para análise histopatológica e coradas pela técnica de hematoxilina e eosina (HE) (Prophet et al. 1992). Colorações especiais, como Gram, Prata metenamina de Grocott e ácido periódico de Schiff (PAS) foram realizadas quando havia suspeita de infecção bacteriana ou micótica, com base nas alterações inflamatórias caracterizadas, principalmente, por broncopneumonia supurativa e placentite necrótica.

\section{Exames de imunofluorescência}

Impressões de secções de rim foram testadas pela imunofluorescência direta (IFD) para Leptospira sp. com anticorpo comercial multivalente, na diluição de 1:20, segundo Miller et al. (1989), em todos os casos.

\section{Exames microbiológicos}

Fragmentos de fígado, pulmão e conteúdo abomasal foram coletados para cultivo bacteriano. Em cultivo aeróbio inespecífico, utilizou-se agar sangue ovino (5\%) e, para isolamento de Brucella sp., meio base de agar sangue (Alton et al. 1988, Timoney et al. 1988) acrescido com $5 \%$ de sangue ovino e antimicrobianos. Para o cultivo de Campylobacter sp. foi utilizado meio BHI (brain heart infusion), conforme Plastridge et al. (1961), em todos os fetos, até 2009. Em casos onde havia suspeita de envolvimento fúngico pulmão, fígado e pele foram encaminhados para o cultivo micológico, em agar sabouraud. A placenta foi encaminhada para exame bacteriológico e/ou micológico em casos onde havia lesões macroscópicas sugestivas de infecção bacteriana ou fúngica.

\section{Exames imuno-histoquímicos}

Todos os fetos analisados foram submetidos ao exame imuno-histoquímico (IHQ) para vírus da diarreia viral bovina (BVDV), independentemente, da presença de lesões macro e microscópicas. A IHQ para Neospora caninum foi realizada em fetos com lesões sugestivas tais como encefalite, miosite e/ou miocardite não supurativas. Já a IHQ para Toxoplasma gondii foi realizada em casos com suspeita clínica e lesões sugestivas como áreas de necrose encefálica associada à inflamação mononuclear.

IHQ para BVDV foi realizada, em fragmentos de timo e encéfalo, com anticorpo monoclonal anti-BVDV (15C5 Syracuse, USA), na diluição de 1:500, em PBS. A recuperação antigênica foi feita com protease XIV de Streptomyces griseus (Sigma, Chemical Co., St Louis, Mo) a $0,05 \%$, por 15 minutos a $37^{\circ} \mathrm{C}$. 0 anticorpo primário foi aplicado durante 50 minutos à temperatura de $37^{\circ} \mathrm{C}$, seguido do anticorpo secundário biotinalado e solução streptavidina conjugada a uma molécula de fosfatase alcalina (LSAB + System AP, Dako Cytomation), por aproximadamente, 20 minutos cada, à temperatura ambiente. Como cromógeno, utilizou-se o Permanent Red (Permanent Red/code 0695, Dako). Controles positivos foram inseridos, simultaneamente, com as lâminas testadas (Schmitz 2006).

IHQ para N. caninum e T. gondii foram realizadas em fragmentos de encéfalo, pelo método da estreptavidina-biotina-peroxidase (LSAB Dako). Após desparafinadas em xilol, as lâminas foram hidratadas em concentrações decrescentes de álcool, lavadas em água destilada, cobertas por solução de peróxido de hidrogênio a $3 \%$ por 15 minutos, para o bloqueio da peroxidase endógena. A recuperação antigênica incluiu 10 minutos de digestão previa com tripsina $1 \%$ a $37^{\circ} \mathrm{C}$ e irradiação em micro-ondas, de uso doméstico, por dois minutos, em potência máxima. Durante essa etapa, as lâminas ficaram imersas em tampão citrato (pH 6,0). Os anticorpos primários policlonais anti-N. caninum e anti-T. gondii foram utilizados na diluição de 1:1000 em tampão fosfato (PBS), durante 45 minutos e a $37^{\circ} \mathrm{C}$. Posteriormente, aplicou-se o anticorpo secundário biotinalado e solução de avidina conjugada com a peroxidase por 30 minutos cada, à temperatura ambiente. A revelação da marcação foi obtida através da utilização do cromógeno 3,3'- diaminobenzidina (DAB - Dako, Carpinteria, CA), por 5-10 minutos. Em cada teste, foram incluídos cortes controles positivos.

Em todos os testes imuno-histoquímicos, para o bloqueio das marcações inespecíficas (background), utilizou-se leite desnatado Molico $^{\circledR}$ a 5\%, durante 15 minutos, à temperatura de ambiente. A contracoloração foi realizada com hematoxilina de Harris, por 1 minuto.

\section{RESULTADOS}

Entre janeiro de 2003 e dezembro de 2011, 490 fetos bovinos foram analisados no SPV-UFRGS. Esses fetos foram provenientes do Rio Grande do Sul (275), Goiás (17), Paraná (12), Santa Catarina e Minas Gerais (9 cada), Mato Grosso do Sul (7), São Paulo (5), Alagoas, Mato Grosso e Rio de Janeiro (1 cada). Em 153 casos, a procedência não foi informada.

A idade gestacional foi determinada em $61 \%$ dos casos (319/490), dos quais $12,5 \%(40 / 319)$ correspondiam ao primeiro trimestre de gestação, $62 \%(198 / 319)$ ao segundo e $25,4 \%(81 / 319)$ ao terceiro. Entre os fetos abortados, 27,7 \% eram fêmeas e 23,1 \%, machos. Em 49,2 \% (241/490) dos casos não foi possível estabelecer, ou não foi informado o sexo fetal. Os fetos distribuíram-se em raças leiteiras $43 \%(211 / 490)$, de corte $6,7 \%$ (33/490) e mistas $1 \%$ (5/490). Em 49,2 \% (241/490) dos casos, não havia informação da raça. 
Dos 490 casos analisados, 53,67 \% (263/490 casos) não tiveram diagnóstico estabelecido, sendo que, em 223 casos, não havia lesões histológicas. Ainda, em 40 casos, as alterações histológicas observadas foram, predominantemente, supurativas, mas não conclusivas. Nesse grupo de fetos, os exames complementares também não foram suficientes para estabelecer o diagnóstico.

Em 227 casos (46,32 \% de 490) com diagnóstico conclusivo, classificou-se a sua etiologia em aborto infeccioso, não infeccioso e outros. As causas infecciosas compreenderam 87,66 \% dos casos (199/227), os quais foram divididos em abortos por protozoários 71,36 \% (162/227), bactérias $13,65 \%$ (31/227), fungos 2,64 \% (6/227), e associações entre esses $0,88 \%(2 / 227)$.

Entre os protozoários, Neospora caninum foi mais frequentemente relacionados com os abortos e respondeu por 32,6 \% (160/490) dos casos. 0 diagnóstico foi fundamentado pela observação de lesões compatíveis como encefalite, miosite e miocardite não supurativas, em associação com IHQ positiva, obtida em $17,5 \%$ dos casos. Um caso de infecção materna por Babesia bovis foi associada com aborto. 0 diagnóstico foi baseado no histórico clínico e esfregaço sanguíneo da fêmea. 0 feto não apresentou nenhuma alteração macro ou microscópica. Um caso de aborto por infecção por Toxoplasma gondii foi associado com extensas áreas de necrose, microgliose e infiltrado linfoplasmocitário, além da presença de cistos e taquizoítos marcados na IHQ anti-T. gondii.

Os agentes bacterianos mais frequentes foram Brucella abortus e Escherichia coli 1,43 \% cada (7/490), Staphylococcus aureus 1,22 \% (6/490), Streptococcus sp. 0,82\% (4/490), Leptospira sp. 0,61 \% (3/490), Arcanobacterium pyogenes, Nocardia sp., Mannhemia sp. e Proteus sp. com $0,2 \%(1 / 490)$, cada.

O diagnóstico de aborto por Leptospira sp. incluiu a detecção de icterícia e hemorragia, além de vasculite placentária severa e nefrite intersticial mononuclear em dois casos e a confirmação por imunofluorescência direta em impressões de secções de rim. A infecção por Brucella sp. foi fundamentada em achados macro e microscópicos associados ao isolamento do agente em tecidos fetais. As principais alterações macroscópicas observadas foram caracterizadas por secreção mucopurulenta na cavidade nasal, traquéia e brônquios; deposição de fibrina na pleura e pericárdio; pulmões não colabados com pontos brancos no parênquima e áreas avermelhadas nos lobos apicais. Em três placentas, havia áreas avermelhadas nas regiões intercotiledonárias, áreas circulares bem delimitadas de coloração amarelo-esbranquiçadas na superfície dos cotilédones e parede espessada. Microscopicamente, broncopneumonia necro-supurativa, pneumonia intersticial e placentite necro-supurativa com áreas de vasculite, mineralização e trombose, foram as lesões mais frequentes em fetos afetados por B. abortus. Para as demais bactérias, o diagnóstico se baseou na observação de lesões histológicas supurativas com crescimento puro ou quantidade abundante do agente bacteriano ao exame microbiológico. Macroscopicamente, pontos esbranquiçados, entre 0,5 e $1,0 \mathrm{~mm}$ de diâmetro, estiveram presentes na pele na maioria dos casos. Histolo- gicamente, dermatite e pneumonia supurativas associadas com colônias bacterianas foram achados frequentes.

Dos quatro casos de aborto micótico, dois foram associados a Aspergillus fumigatus, um a Geotrichum candidum e um a Zigomicetos. As alterações macroscópicas estiveram presentes, principalmente, na pele e caracterizaram-se por lesões branco-acinzentadas circulares distribuídas, especialmente, na cabeça e nuca e, quando presentes na placenta eram associadas com espessamento de cotilédones. Histologicamente observaram-se dermatite e placentite supurativas com estruturas de hifas intralesionais. Para o diagnóstico de aborto micótico, foram consideradas as avaliações macro e microscópica, inclusive com aplicação de colorações especiais como prata metenamina de Grocott e ácido periódico de Schiff (PAS), além do cultivo, principalmente, de placenta e conteúdo abomasal.

Infecção por BVDV foi observadas em um caso, em co-infecção com Neospora caninum, e o diagnóstico viral foi baseado na IHQ anti-BVDV. Associação entre agentes foi observada ainda entre $N$. caninum e Escherichia coli em um caso. Esse tipo de diagnóstico foi estabelecido quando o feto apresentou lesões compatíveis e resultado positivo em exames complementares para dois agentes distintos.

Causas não infecciosas foram identificadas em 6,6 \% dos casos (15/227), dos quais seis distocias e três casos de trauma/estresse, de gestações gemelares e de rupturas hepáticas. 0 diagnóstico das causas não infecciosas fundamentou-se nos resultados negativos nos exames realizados, na ausência de alterações macro e microscópicas sugestivas de agentes infecciosos e nos dados clínicos como estresse materno anterior ao aborto e gestação gemelar. As anomalias congênitas foram classificadas em uma categoria a parte, uma vez que podem ser causadas tanto por agentes infecciosos, quanto por não infecciosos e estiveram presentes em 5,7\% (13/227) com observação de alterações como osteopetrose, Amorfus globosus, diprosopo, palatosquise, artrogripose, hipotricose, bragnatismo com agenesia renal, espinha bífida e condrodisplasia, além de anomalias múltiplas cardíacas, pulmonares e articulares em um feto. Dados sobre anomalias congênitas diagnosticadas no SPV-UFRGS foram parcialmente publicadas por Pavarini et al. (2008).

0 Quadro 1 apresenta as principais causas de aborto bovino estudadas. A Figura 1 apresenta a frequência de casos de aborto com diagnóstico conclusivo e com causas infecciosas e não infecciosas.

\section{DISCUSSÃO}

Em 46,7\% dos abortos estudados foi possível relacionar um agente etiológico, diferente dos 51,5\% observados por Corbellini et al. (2006a). Na maioria dos estudos realizados, somente em 30 a $40 \%$ dos fetos obtém-se diagnóstico etiológico definitivo. Isso, em parte, ocorre devido à multiplicidade de causas envolvidas (Kirkbride 1990), mas, especialmente, decorre das dificuldades inerentes à identificação e ao isolamento dos agentes, o que, em determinados casos, é ainda mais prejudicado pela autólise fetal (Fernandes 1998).

O diagnóstico de Neospora caninum em 32,6\% dos casos evidenciou, a importância dessa causa de aborto nos re- 
Quadro 1. Causas de aborto bovino diagnosticadas no Setor de Patologia Veterinária da UFRGS no período de 2003 à 2011

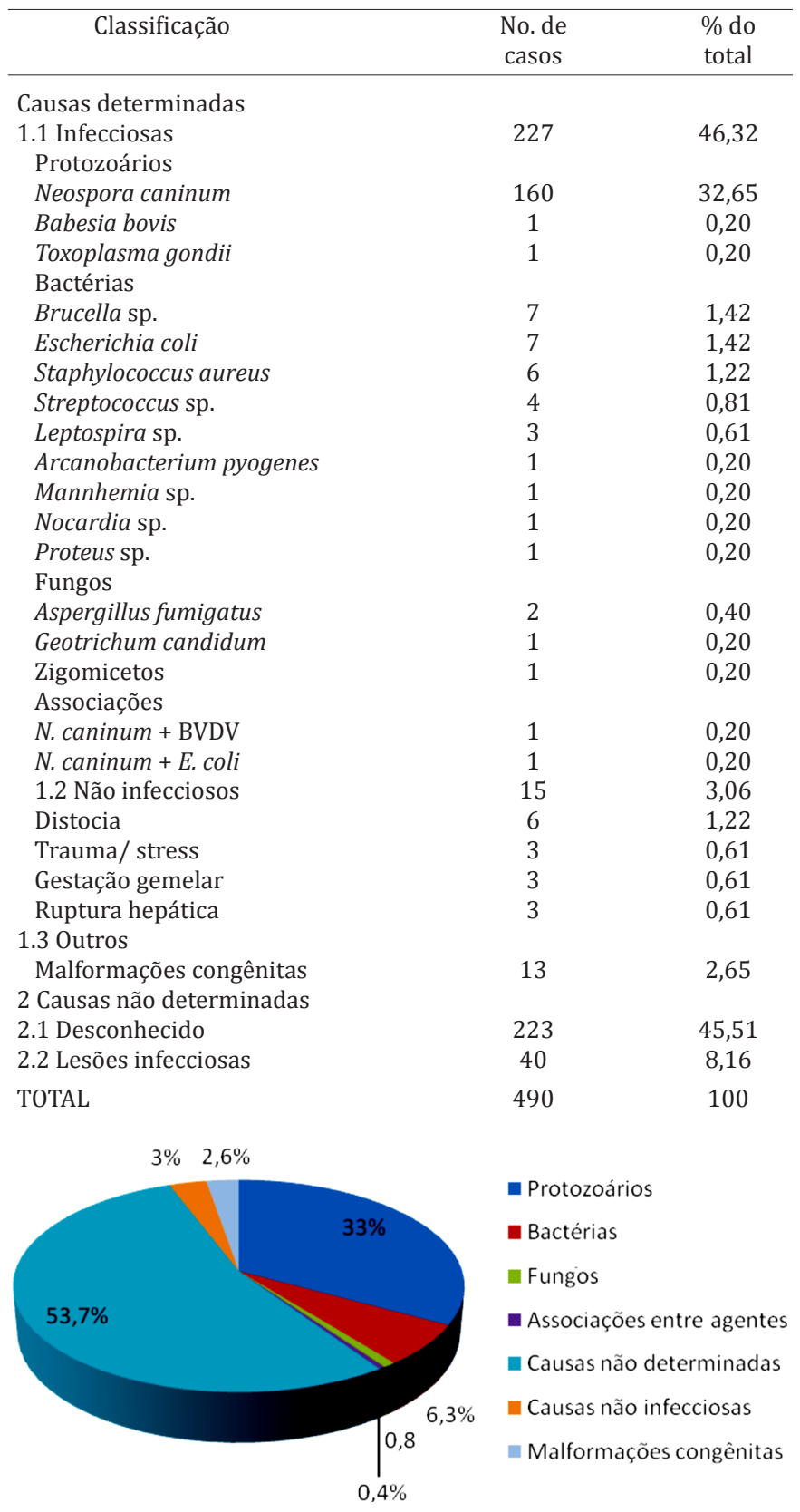

Fig.1. Frequência de causas não determinadas, não infecciosas, infecções por protozoários, bactérias, fungos e associações entre agentes diagnosticados em fetos bovinos abortados no período de 2003-2011.

banhos bovinos leiteiros brasileiros. Estudos têm demonstrado variações entre 12 e $77 \%$ na taxa de infecção por $N$. caninum (Dubey 2003). Entretanto, $20 \%$ dos abortos bovinos na Califórnia (Anderson et al. 2000) e 13 a 39,1\% dos abortos bovinos no Brasil (Corbellini et al. 2006a, 2002), respectivamente, têm sido, consistentemente, ligados ao protozoário. 0 diagnóstico da infecção por $N$. caninum foi realizado pela associação de achados característicos da infecção. Segundo, Anderson et al. (2000) e Dubey (2003), o diagnóstico de $N$. caninum pode ser fundamentado na de- tecção histopatológica de encefalite multifocal, em combinação com miocardite e miosite, pois tais lesões são, fortemente, sugestivas da infecção. No entanto, a possibilidade da infecção por N. caninum em fetos nos quais as lesões não são encontradas no cérebro necessitam ser consideradas (Corbellini et al. 2006a, Pescador et al. 2007a).

A infecção por $N$. caninum foi confirmada através da IHQ em 17,5\%. Corbellini et al. (2000) descreveram positividade em $10 \%$ dos 30 fetos testados em IHQ anti- $N$. caninum. Cabral et al. (2009) observaram 8,6\% de positivos na IHQ em 75 fetos com lesões compatíveis com o agente. A IHQ é bastante especifica; entretanto, pouco sensível (Van Maanen et al. 2004). A ausência de taquizoítos ou cistos de $N$. caninum em tecidos com lesões características do protozoário não descarta a possibilidade do aborto ter sido causado por esse agente, pois sua distribuição pode ser esporádica e esparsa nos tecidos (Thilsted \& Dubey 1989). Além disso, outras causas como presença de reações inflamatórias e autólise podem afetar a morfologia e antigenicidade do protozoário, além de influenciar na marcação (Hattel et al. 1998).

Infecção materna por Babesia sp. foi associados a um aborto. A expulsão fetal ocorre, principalmente, devido à hipertermia relacionada a infecção materna.

Toxoplasma Gondii é um protozoário, frequentemente, associado com abortos em ovinos e caprinos; entretanto, há poucos relatos do aborto bovino por esse agente (Gottstein et al. 1998, Sager et al. 2001, Moré et al. 2008). No presente estudo, as lesões observadas nesse feto restringiam-se ao encéfalo. Em caprinos e ovinos infectados por T. gondii, as lesões microscópicas são, particularmente, observadas no cérebro, fígado e pulmão (Pescador et al. 2007b, Caldeira et al 2011). Encefalite não supurativa e gliose multifocal têm sido, frequentemente, descritas nessa infecção (Pescador et al. 2007b, Caldeira et al. 2011), como também foi confirmado nesse estudo.

Poucos dados a respeito da prevalência de Brucella abortus em fetos abortados são disponíveis e há grande variação nos testes utilizados nos estudos. Campero et al. (2003) detectaram a infecção por B. abortus em 7,9 \% de 354 fetos bovinos analisados na Argentina. Cortez et al. (2006), no Brasil, analisaram 124 amostras por PCR e detectaram DNA de Brucella spp. em 13,7 \% delas. Em 70 $(5,56 \%)$ de 1259 fetos bovinos abortados submetidos à bacteriologia, isolou-se B. abortus (Genovez et al. 2006).

Neste estudo, Leptospira sp. foi identificada por IFD em $0,61 \%$ dos abortos. Isto difere dos dados de Cortez et al. (2006) que detectaram ácidos nucléicos de Leptospira sp. por PCR em 3,6 \% de amostras de 124 fetos analisados e provenientes de estados brasileiros. Já Langoni et al. (1999) isolaram Leptospira sp. em 12,5 \% dos 120 fetos analisados, em São Paulo. A menor taxa de detecção de Leptospira sp. observada, em comparação com os demais estudos, pode ser devida ao tipo de teste confirmatório utilizado, que, apesar de apresentar resultados satisfatórios para a detecção do agente, pode apresentar resultados falso negativos influenciados pela fragilidade do agente frente a processos como autólise e congelamento, por exemplo. A ausência de lesões em fetos abortados não deve excluir o 
diagnóstico de Leptospira sp., pois sorovar hardjo é bem adaptado a bovinos e pode não causar lesões significativas na espécie (Thiermann 1982).

Diversas espécies de bactérias oportunistas podem causar septicemia e aborto esporádicos em animais de produção (Corbellini et al. 2006b). Escherichia coli, Staphylococcus spp., Streptococcus spp., Actinomyces pyogenes, Nocardia sp., Mannhemia sp. e Proteus sp. foram isolados e associados com abortos bovinos nesse estudo.

Infecções micóticas podem causar placentite necrosante e aborto em diversas espécies de animais (Ainsworth \& Austwick 1973, Zook \& Migaki 1985). Perdas econômicas significativas podem ser decorrentes dessas infecções, inclusive prevalência de aborto micótico da ordem de 24,9\% já foi relatada (Ainsworth \& Austwick 1973). Aspergillus fumigatus, diagnosticado em dois casos,é a principal espécie encontrada em casos de aborto micótico em bovinos.

Vírus como BVDV e BHV-1, frequentemente associados a abortos bovinos não tiveram grande importância nos casos analisados. Apesar da realização de testes imuno-histoquímicos para detecção de BVDV em todos os fetos analisados, somente um caso de infecção viral foi identificado, e este em associação com $N$. caninum. 0 diagnóstico de infecção por BHV-1 em fetos bovinos é realizado pela observação de lesões histopatológicas caracterizadas por necrose hepática e posterior realização do teste de IHQ, entretanto no período analisado tais lesões não foram observadas em nenhum caso.

Diferentes associações entre agentes foram observadas neste trabalho. 0 envolvimento de múltiplos agentes em abortos bovinos tem sido relatado (Caldow 1998). Infecção por $N$. caninum tem sido associada a diferentes agentes, tais como BVDV e BHV-4 (Dubey et al. 1990; Nietfeld et al. 1992). Torna-se difícil indicar qual infecção é a principal responsável pelo aborto e, se a sinergia entre os agentes concorrentes pode ser mais prejudicial para a sobrevivência fetal (Corbellini et al. 2006a).

Estudos etiológicos em fetos bovinos abortados revelam que a maioria dos casos com causa determinada se deve a agentes infecciosos (Anderson et al. 1990, Kirkbride 1992). Entretanto, acredita-se que as causas não infecciosas sejam subestimadas, pois há grande dificuldade no diagnóstico destas, já que não apresentam lesões histológicas e há, em sua maioria, necessidade de estudo epidemiológico detalhado do animal e da propriedade. A incidência de distocia em bovinos varia de 3 a $25 \%$ e ocorre, especialmente, em novilhas de primeira cria de raças de maior porte (Smith 2006). A falha da dilatação cervical é a causa mais comum de distocia bovina (Noakes 1992). Os fetos, geralmente, morrem devido à asfixia e as lesões observadas são áreas de edema sublingual e trombos de fibrina em vasos cerebrais. Três casos foram associados ao histórico de trauma ou stress da mãe. Nenhum desses fetos apresentou lesões macro e microscópicas, além de apresentarem resultados negativos para todos os exames complementares realizados. Em três fetos, ruptura hepática e hemoperitônio foram observados. Acredita-se que esses fetos possam ter sofrido trauma intrauterino, ou no momento da expulsão uterina. Três casos foram associados à gestação gemelar de fetos de sexos distintos. Usualmente, a gemelaridade em bovinos é associada com distocia, a qual não raramente, leva à morte de um, ou ambos os fetos.

Os resultados do presente estudo demonstram as principais causas de perdas fetais em bovinos. Foi reforçada a importância de $N$. caninum como causa de aborto nessa espécie. Essa investigação incluiu o registro de infecções por agentes não associados, previamente, com abortos em bovinos, o que evidencia a necessidade da continuidade dos estudos. Enfatiza-se a importância de estudos epidemiológicos desses casos distintos, tanto para incremento na eficiência diagnóstica dessas causas de aborto, em especial, das não infecciosas ainda pouco elucidadas.

\section{REFERÊNCIAS}

Ainsworth G.C. \& Austwick P.K.C. 1973. Mycotic abortion, p.74-80. In: Ibid. (Eds), Fungal Diseases of Animals. $2^{\text {nd }}$ ed. Commonwealth Agriculture Bureaux, Farnham Royal, Slough, Uk.

Alton G.G., Jones L.M., Angus R.D. \& Verger J.M. 1988. Techniques for the Brucellosis Laboratory. Institut National de la Recherche Agronomique, Paris, p.169-174.

Anderson M.L., Andrianarivo A.G. \& Conrad P.A. 2000. Neosporosis in cattle. Anim. Reprod. Sci. 60/61:417-431.

Anderson M.L., Blanchard P.C., Barr B.C. \& Hoffman R.L. 1990. A survey of causes of bovine abortion occurring in the San Joaquin Valley, California. J. Vet. Diagn. Invest. 2:283-287.

Barr C.B., Anderson M.L., Blanchard P.C., Daft B.M., Kinde H. \& Conrad P.A. 1990. Bovine fetal encephalitis and myocarditis associated with protozoal infections. Vet. Pathol. 27:354-361.

Cabral A.D., Camargo C.N., Galleti N.T.C., Okuda L.H., Pituco E.M. \& Del Fava C. 2009. Diagnosis of Neospora caninum in bovine fetuses by histology, immunohistochemistry, and nested-PCR. Revta Bras. Parasitol. Vet. 18(4):14-19.

Caldeira F.H.B., Ubiali D.G., Godoy I., Dutra V., Aguiar D.M., Melo A.L.T., Riet-Correa F., Colodel E.M. \& Pescador C.A. 2011. Outbreak of caprine abortion by Toxoplasma gondii in Midwest Brazil. Pesq. Vet. Bras. 31(11):933-937.

Caldow G.L. 1998. Bovine abortion outbreak associated with Neospora and other infectious agents. Vet. Rec. 142:118-119.

Campero C.M., Moore D.P., Odeon A.C., Cipolla A.L. \& Odriozola E. 2003. Aetiology of bovine abortion in Argentina. Vet. Res. Commun. 27:259-269.

Corbellini L.G., Driemeier D., Cruz C. \& Dias M.M. 2000. Aborto Bovino por Neospora caninum no Rio Grande do Sul. Ciência Rural 30(50): 863-868.

Corbellini L.G., Driemeier D., Cruz C.E.F., Gondim L.F.P. \& Wald V. 2002. Neospora caninum as a cause of abortion in dairy cattle in Rio Grande do Sul, southern Brazil. Vet. Parasitol. 103:195-202.

Corbellini L.G., Pescador C.A., Frantz F., Wunder E., Steffen D.J., Smith D.R. \& Driemeier D. 2006a. Diagnostic survey of bovine abortion with special reference to Neospora caninum infection: Importance, repeated abortion and concurrent infection in aborted fetuses in southern Brazil. Vet. J. 172(1):114-120.

Corbellini L.G., Pescador C.A., Frantz F.J., Cardoso M. \& Driemeier D. 2006b. Staphylococcus spp. abortion: skin lesions caused by Staphylococcus aureus infection in an aborted bovine-fetus. Vet. Res. Commun. 30:717-721.

Cortez A., Castro A.M.G., Heinemann M.B., Soares R.C., Leite R.C., Scarcelli E., Genovez M.E., Alfieri A.A. \& Richtzenhain L.J. 2006. Detecção de ácidos nucléicos de Brucella spp., Leptospira spp., herpesvirus bovino e vírus da diarréia viral bovina, em fetos bovinos abortados e em animais mortos no perinatal Arq. Bras. Med. Vet. Zootec. 58(6):1226-1228.

Dubey J.P. 2003. Neosporosis in cattle. J. Parasitol. 89:542-556.

Dubey J.P., Miller S., Lindsay D.S. \& Topper L.J. 1990. Neospora caninum associated myocarditis and encephalitis in an aborted calf. J. Vet. Diagn. Invest. 2:66-69. 
Fernandes C.G. 1998. Doenças da reprodução. In: Riet-Correa F., Schild A.L. \& Mendez M.D.C. (Eds), Doença de Ruminantes e Eqüinos. Ed. Universitária/UFPEL, Pelotas. 651p.

Genovez M.E., Scarcelli E., Cardoso M.V., Piatti R.M., Campos F.R., Teixeira S.R., Castro V., Gotti T.B. \& Batista C.A. 2006. Main bacterial agents as cause of abortions in bovines in Brazil. Proc. XXIV World Buiatric Congress, Nice.

Gottstein B., Hentrich B., Wyss R., Thür B., Busato A., Stärk K.D. \& Müller N. 1998. Molecular and immunodiagnostic investigations on bovine neosporosis in Switzerland. Int. J. Parasitol. 28(4):679-91.

Hattel A.L., Castro M.D., Gummo J.D., Weinstock D., Reed J.A. \& Dubey J.P. 1998. Neosporosis-associated bovine abortion in Pennsylvania. Vet. Parasitol. 74:307-313.

Hubbert W.T., Dennis S.M., Adams C.J.W.M., Bierschwal C.J., Biggers J.D., Carrol E.J., Dunne H.W., Hutton N.E., Kendrick J.W., Kenney R.M., Kirkham W.W., Leipold H.W., Lingard D.R., McDonald L.E., Miner M.L., Mossman H.W., Murdick P.W., Oberst F.H., Priester W.A., Ramge J.C., Simon J., Smith R.E., Swift B.L., Wagner W.C., Williams E.I. \& Zemjanis R. 1972. Recommendations for standardizing bovine reproductive terms. Cornell Vet. 62:217-237.

Jamaluddin A.A., Case J.T., Hird D.W., Blanchard P.C., Peauroi J.R. \& Anderson M.L. 1996. Dairy cattle abortion in California: evaluation of diagnostic laboratory data. J. Vet. Diagn. Invest. 8:210-218.

Kirkbride C.A. 1990. Laboratory Diagnosis of Livestock Abortion. $3^{\text {rd }}$ ed. Iowa State University Press, Ames. 260p.

Kirkbride C.A. 1991. Causes and prevention of bovine abortion. Bov. Proceed. 23:75-80

Kirkbride C.A. 1992. Etiologic agents detected in a 10-year study of bovine abortions and stillbirths. J. Vet. Diagn. Invest. 4(2):175-180.

Langoni H., Souza L.C., Silva A.V., Luvizotto M.C., Paes A.C. \& Lucheis S.B. 1999. Incidence of leptospiral abortion in Brazilian dairy cattle. Prev. Vet. Med. 40:271-275.

Miller D.A., Wilson M.A. \& Kirkbride C.A. 1989. Evaluation of multivalent leptospira fluorescent antibody conjugates for general diagnostic use. J. Vet. Diagn. Invest. 1(2):146-149.

Miller R.B. 1987. Diagnosing the Cause of Bovine Abortion. Bov. Pract. 22:98-101.

Moré G., Basso W., Bacigalupe D., Venturini M.C. \& Venturini L. 2008. Diagnosis of Sarcocystis cruzi, Neospora caninum and Toxoplasma gondii infecctions in cattle. Parasitol. Res. 102(4):671-675.

Nietfeld J.C., Dubey J.P., Anderson M.L., Libal M.C., Yaeger M.J. \& Neiger R.D. 1992. Neospora-like protozoan infection as a cause of abortion in dairy cattle. J. Vet. Diagn. Invest. 4:223-226.
Noakes D.E. 1992. Fertilidade e Obstetrícia nos Bovinos. Andrei Editora, São Paulo, p.43-49 e 72-101.

Pavarini S.P., Sonne L., Antoniassi N.A.B., Santos A.S., Pescador C.A., Corbellini L.G. \& Driemeier D. 2008. Anomalias congênitas em fetos bovinos abortados no Sul do Brasil. Pesq. Vet. Bras. 28(3):149-154.

Pescador C.A., Corbellini L.G., Oliveira E.C., Raymundo D.L. \& Driemeier D. 2007a. Histopathological and immunohistochemistry aspects of Neospora caninum diagnosis in bovine aborted fetuses. J. Vet. Parasitol. 150:159-163.

Pescador C.A., Oliveira E.C., Pedroso P.M.O, Bandarra P.M., Okuda L.H., Corbellini L.G. \& Driemeier D. 2007b. Perdas reprodutivas associadas com infecção por Toxoplasma gondii em caprinos no sul do Brasil. Pesq. Vet. Bras. 27:167-171.

Plastridge W.N., Koths M.E. \& Williams L.F. 1961. Antibiotic mediums for the isolation of vibrios from bull semen Am. J. Vet. Res. 22:867-871.

Prophet E.B., Mills B., Arrington J.B. \& Sobin L.H. 1992. Laboratory Methods in Histotechnology. American Registry of Pathology, Armed Forced Institute of Pathology, Washington, DC. 279p.

Sager H., Fischer I., Furrer K., Strasser M., Waldvogel A., Boerlin P., Audigé L. \& Gottstein B. 2001. A Swiss case-control study to assess Neospora caninum-associated bovine abortions by PCR, histopathology and serology. Vet. Parasitol. 102:1-15.

Schmitz M. 2006. Caracterização patológica e imunoistoquímica da infecção pelo vírus da diarréia viral bovina. Dissertação de Mestrado, Faculdade de Medicina Veterinária, Universidade Federal do Rio Grande do Sul, Porto Alegre. 63p.

Smith B.P. 2006. Medicina Interna de Grandes Animais. Manole, São Paulo, p.224-226.

Thiermann A.B. 1982. Experimental leptospira infection in pregnant cattle with organisms of the Hebdomadis serogroup. Am. J. Vet. Res. 43:780-784.

Thilsted J.P. \& Dubey J.P. 1989. Neosporosis-like abortions in a herd of dairy cattle. J. Vet. Diagn. Invest. 1:205-209.

Timoney J.F., Gillespie J.H., Scott F.W. \& Barlough J.E. 1988. Hagan and Bruner's Microbiology and Infectious Diseases of Domestic Animals. $8^{\text {th }}$ ed. Cornell University Press, Ithaca. 951p.

Van Maanen C., Wouda W., Schares G., Von Blumröder D., Conraths F., Norton R., Williams D.J.L., Esteban-Redondo I., Ines E.A., Mattsson J.G., Björkman C., Fernández-García A., Ortega-Mora L.M., Müller N., Sager H. \& Hemphill A. 2004. A interlaboratory comparison of immunohistochemistry and PCR methods for detection of Neospora caninum in bovine foetal tissues. Vet. Parasitol. 126:351-364.

Zook B.C. \& Migaki G. 1985. Aspergillosis in animals, p.207-256. In: Al-Doory Y. \& Waagner G.E. (Eds), Aspergillosis. Charles C. Thomas Publisher, Springfield, Illinois. 